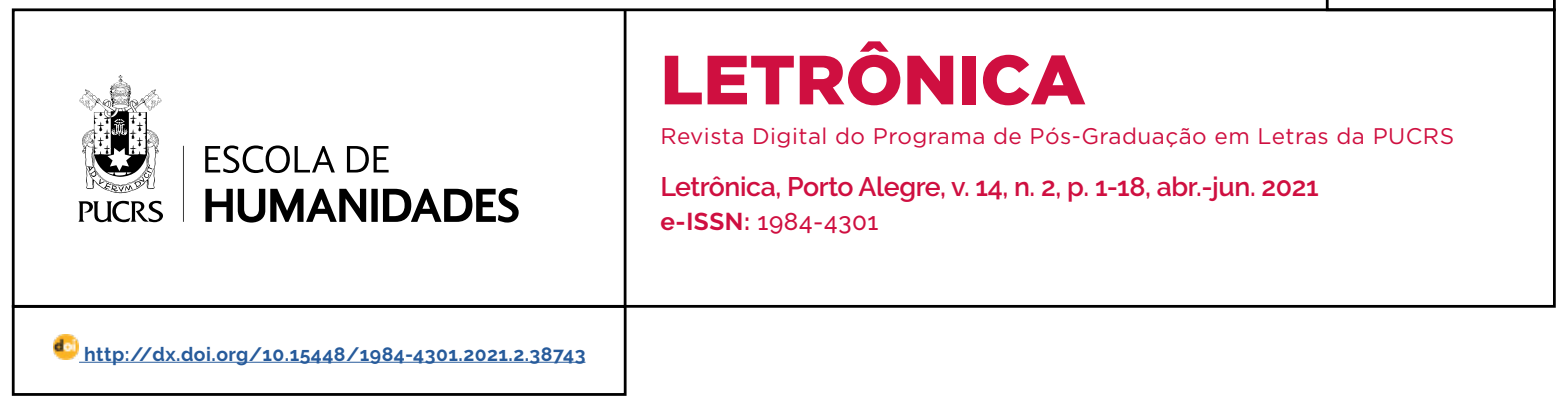

SEÇÃO: ARTIGOS

\title{
Evidências de validade e normas de desempenho na Tarefa de Escrita de Palavras e Pseudopalavras (TEPP) para estudantes do $4^{\circ}$ e $6^{\circ}$ anos
}

\author{
Evidence of validity and normative data in the Word and Pseudoword Spelling Task \\ (TEPP) for 4th and 6th grade students
}

\section{Jaqueline de Carvalho Rodrigues $^{1}$ \\ orcid.org/0000-0001-9947-4705 \\ jaqueliner@unisinos.br}

\section{Lisiane França Garcia \\ Franquilin Pereira ${ }^{2}$ orcid.org/0000-0003-3724-786X \\ Lisifranquilin@gmail.com}

\section{Jerusa Fumagalli de \\ Salles ${ }^{3}$ \\ orcid.org/0000-0003-0877-488X \\ jerusafsalles@gmail.com}

Helena Vellinho Corso ${ }^{3}$

orcid.org/0000-0002-2476-0923

hvcorso@gmail.com.

Luciana Vellinho Corso ${ }^{3}$

orcid.org/0000-0001-6384-3994

luciana.corso@ufrgs.br

Recebido em: 30/07/2020.

Aprovado em: 14/12/2020.

Publicado em: 10/8/2021.
Resumo: Este estudo apresenta o desempenho de alunos do $4^{\circ}$ e $6^{\circ}$ anos na Tarefa de Escrita de Palavras e Pseudopalavras (TEPP). Analisaram-se evidências de validade baseadas na relação com critério (correlação com idade, e comparação de grupos por ano de escolaridade e sexo), validade convergente por meio de correlações da TEPP com o Ditado Balanceado e com o Instrumento de Avaliação Neuropsicológica Breve Infantil NEUPSILIN- Inf, além de apresentar dados normativos para alunos de $4^{\circ}$ e $6^{\circ}$ anos do Ensino Fundamental. Participaram 181 estudantes de escolas públicas, sendo 55,8\% meninas, com idades entre 9 e 12 anos. Identificaram-se maiores escores para os estudantes mais velhos e de maior escolaridade, além de maiores escores das meninas em algumas medidas da TEPP, reforçando a validade de critério do instrumento. A TEPP mostrou estar relacionada com medidas de ortografia, atenção, memória, funções executivas, linguagem e habilidades aritméticas, demonstrando evidências de validade convergente. São apresentados os dados normativos da TEPP, considerando os dois anos escolares dos participantes, contribuindo para os profissionais que utilizam este instrumento na prática clínica, como também no âmbito educacional. Palavras-chave: Linguagem escrita. Neuropsicologia. Propriedades psicométricas.

Abstract: This study presents the performance of 4 th and 6th grade students in the Task of Spelling Words and Pseudowords (TEPP). It was analyzed validity evidence based on the relationship with criteria (correlation with age, and comparison of groups by year of schooling and gender), as well as convergent validity through correlations among TEPP with the Balanced Dictation instrument and the Child Neuropsychological Assessment Instrument NEUPSILIN-Inf. In addition, it is presented normative data for students of 4 th and 6th grades of Elementary School. It included 181 students from public schools, being $55.8 \%$ girls, with aged between 9 and 12 years old. Higher scores were identified for older and more educated students; in addition higher scores were found for girls in some TEPP measures, reinforcing the criterion validity of the instrument. The TEPP instrument has been related to spelling, attention, memory, executive functions, language and arithmetic skills, showing evidence of convergent validity. The normative data of TEPP are presented, considering the two school years of the participants, contributing to the professionals who use this instrument in clinical practice and also in the educational setting.

Keywords: Written language. Neuropsychology. Psychometric properties. 


\section{Introdução}

A escrita, por meio das habilidades de grafia, ortografia e produção textual, é uma competência bastante complexa. O desempenho eficiente nesta área pressupõe um conjunto de condições individuais, ambientais e escolares, atuando de forma integrada. Do ponto de vista individual, ela apoia-se em subdominios ligados a aspectos cognitivos, metacognitivos, linguísticos e percepto-motores que dão sustentação a esta aprendizagem (ARFÉ; DOCKRELL; DE BERNARDI, 2016; MALUF; CARDOSO-MARTINS, 2013). Tal complexidade oferece desafios, em maior ou menor grau, para todos os aprendizes. No entanto, há uma parcela grande de alunos para os quais a escrita causa muitas dificuldades, compromete o rendimento escolar e, consequentemente, o futuro profissional (CAPELLINI; CONRADO, 2009; MOOJEN, 2009).

O cenário de dificuldades enfrentadas com esta área do conhecimento, desde o início da trajetória escolar de muitos alunos, fica evidente com os resultados dos censos. O último levantamento de dados feito pela Avaliação Nacional da Alfabetização (ANA), em 2016, que tem como público-alvo os alunos matriculados no $3^{\circ}$ ano do Ensino Fundamental, mostrou que 33,85\% apresentaram proficiência insuficiente em escrita (INEP, 2018a). Já a Avaliação Nacional do Rendimento Escolar (ANRESC), também conhecida como Prova Brasil, realizada com alunos do $5^{\circ} \mathrm{e}$ $9^{\circ}$ anos do Ensino Fundamental das escolas públicas brasileiras, em 2017 - último levantamento de dados efetuado, aponta que os estudantes matriculados no $5^{\circ}$ ano do Ensino Fundamental alcançaram média de 215 em Língua Portuguesa, classificando-se no nivel 4 de uma escala que alcança o nivel 9 de proficiência (INEP, 2018b). A nivel regional, o Sistema de Avaliação do Rendimento Escolar do Rio Grande do Sul (SAERS), em seu levantamento de dados de 2016, revela que, para $02^{\circ}$ ano do Ensino Fundamental, cerca de $9 \%$ dos alunos da rede estadual classificaram-se em escrita no nível denominado "abaixo do básico" e cerca de 34\% no nível "básico", o que representa um padrão de desempenho muito abaixo do mínimo esperado e basilar para o ano de escolaridade e componentes avaliados (RIO GRANDE DO SUL, 2016).

\section{A aprendizagem da escrita}

Para escrever a criança precisa conhecer as letras (grafemas) e representá-las manualmente (grafia), além de desenvolver a habilidade de relacionar os sons (fonemas) às combinações de letras (morfemas), formando as palavras (léxico). O domínio das convenções ortográficas da escrita no Português Brasileiro é um processo gradual, já que há correspondências regulares entre fonemas e grafemas, mas há contextos ortográficos complexos em que tal correspondência é irregular (CARDOSO-MARTINS, GONÇALVES, 2017).

Pode-se encontrar, por exemplo, uma mesma letra com diferentes fonemas correspondentes (por exemplo o "x" em "xícara", "táxi", "exame", "extra"). Nesse sentido, o aprendizado da linguagem escrita envolve o desenvolvimento de habilidades cognitivas relacionadas à sensibilidade da criança à organização da língua em seus diferentes aspectos: fonológico, morfossintático, semântico e pragmático (CORREA, 2010; GUIMARÃES; BARBOSA; KRUSZIELSKI, 2019).

Especificamente, são as habilidades metalinguísticas que permitem à criança tomar a língua como objeto de reflexão. Dentre essas, a consciência fonológica e a consciência morfológica têm um papel muito importante (GUIMARÃES et al., 2019). A primeira permite a escrita das regularidades grafofonêmicas, e também impacta o entendimento das regularidades de contexto la relação grafofonêmica aqui depende da posição da sequência sonora e sua representação na palavra, por exemplo o uso do "r" ou "rr"). A segunda permite à criança decidir sobre a grafia de palavras quando diferentes morfemas possuem uma mesma sequência sonora (por exemplo, "baronesa" e "beleza"), ou quando é possivel derivar a escrita de uma palavra irregular a partir do conhecimento de como se escrevem palavras cognatas, como saber escrever "geladeira" por conhecer a palavra "gelo" (CORREA, 2010).

Segundo o modelo linguístico de dupla rota proposto por Coltheart (2006), a escrita de pa- 
lavras é realizada por meio de dois tipos de processamento cognitivo: pela rota lexical, que pode envolver o conhecimento do significado da palavra (acesso semântico), ou pela rota fonológica. A escrita com mediação da rota lexical é realizada quando escrevemos palavras que são familiares na língua, ou seja, são recorrentemente visualizadas e memorizadas. Por exemplo, a palavra "água" é mais frequente que a palavra "tulipa", por ser frequentemente vista em supermercados, bares ou na televisão em relação a esta.

Ainda, a rota lexical é exigida quando precisamos escrever palavras irregulares, ou seja, que podem ter representações fonológicas ambiguas. Por exemplo, podemos escrever "bicho" ou "bixo", que dependendo do grafema utilizado, mudaria o significado da palavra escrita. Portanto, utilizamos predominantemente a rota lexical quando necessitamos resgatar da memória (léxico) a combinação dos grafemas das palavras para serem adequadamente escritas (ELLIS, 1995). Na escrita com mediação fonológica, os sons das palavras ouvidas (em uma tarefa sob ditado) são convertidos em grafemas (conversão fonema-grafema). Assim, utilizamos predominantemente esta rota quando escrevemos palavras não familiares (que inclusive não sabemos o seu significado) e pseudopalavras (palavras que não existem no léxico de uma língua, por exemplo, "desmo") (COLTHEART, 2006).

Cardoso-Martins e Gonçalves (2017) analisaram o desempenho de alunos do $2^{\circ}$ ao $5^{\circ}$ ano do Ensino Fundamental para escrever palavras que apresentam irregularidades ortográficas de natureza morfossintática. As pesquisadoras avaliaram 309 crianças com uma tarefa de ditado composto por dois grupos de palavras de acordo com sua regularidade (regulares versus irregulares nas relações fonema/grafema de escrita).

As autoras concluiram que a aquisição de padrões ortográficos influenciados pela morfossintaxe desenvolve-se lentamente no português brasileiro, conforme a criança vai sendo exposta a materiais escritos. É a partir do $4^{\circ}$ ano do Ensino Fundamental que as crianças parecem se beneficiar do conhecimento morfossintático para escrever palavras irregulares. Ainda, para escrever corretamente correspondências fonema/grafema inconsistentes é importante que elas sejam estimuladas a ler esse tipo de estímulo. Contudo, os livros infantis nas séries iniciais apresentam poucas palavras irregulares na sua escrita, o que pode gerar dificuldades para as crianças.

A aprendizagem da escrita ocorre a partir da integração de diferentes habilidades linguístico- cognitivas. A produção do texto, objetivo último da escrita, envolve dois níveis de organização: um referente ao sentido global, ou seja, a coerência, que supõe atividades metacognitivas de planejamento e monitoramento, e outro relacionado à estruturação linguística. Este último nivel se refere tanto ao ato de escrever, como ao domínio das convenções linguísticas. O respeito às convenções ortográficas é condição para a legibilidade do texto, sem a qual a inteligibilidade dele não pode ser alcançada (CORREA, 2010).

A dificuldade significativa na aprendizagem da escrita é apontada pelo Manual Diagnóstico e Estatístico de Transtornos Mentais (DSM-5) como um transtorno especíico da aprendizagem, com prejuizo na escrita, em um ou mais dos seguintes aspectos: dificuldade com a ortografia e dificuldade de expressão escrita, cujas manifestações podem se dar em grau leve, moderado ou grave (APA, 2013). A importância de uma avaliação cuidadosa para o diagnóstico dos transtornos de aprendizagem, nas diversas áreas acadêmicas, é destacada pelo DSM-5 e se dá pelo uso de testes padronizados e normatizados para sexo, idade, escolaridade ou grupos culturais ou linguísticos (DORNELES et al., 2014). Esta recomendação reforça o quanto o Brasil precisa avançar para alcançar diagnósticos mais precisos, e o quanto a carência de instrumentos padronizados e normatizados coloca país em desvantagem.

Portanto, a criação de ferramentas de avaliação da escrita se torna indispensável e necessária e pode ser considerada uma estratégia potente para o enfrentamento do difícil cenário acima referido. Isto porque somente uma avaliação precisa e cuidadosa possibilita uma intervenção adequada, assim como a prevenção de problemas de aprendizagem (COR- 
SO; DORNELES, 2013). Avaliar a escrita, entretanto, também é uma tarefa complexa, já que um único instrumento não dá conta de mensurar os diferentes subdomínios desta habilidade (FLETCHER et al., 2009). Nesse sentido, uma abordagem de avaliações múltiplas sobre esta área do conhecimento tem o potencial de reduzir as dificuldades encontradas com o uso de uma única avaliação, em um único momento (FLETCHER et al., 2009).

Sabe-se que um dos desafios para a pesquisa brasileira é a escassez de instrumentos de avaliação validados e normatizados em lingua portuguesa, pensados a partir da realidade socioeconômica e cultural brasileira (SALLES et al., 2014). Para suprir tal lacuna, a TEEP - Tarefa de Escrita de Palavras e Pseudopalavras (RODRIGUES; MINÁ; SALLES, 2017) foi construida, validada e normatizada para uso com adultos e idosos brasileiros. A amostra normativa compreendeu 147 adultos, entre 34 e 82 anos, com os seguintes anos de estudo formal: de 1 a 5 anos, de 6 a 10 anos e de 11 ou mais anos.

Com o intuito de ampliar tal amostra normativa, englobando crianças e adolescentes, este estudo objetivou apresentar o desempenho de alunos do $4^{\circ}$ e $6^{\circ}$ ano na TEPP. Especificamente, buscou-se analisar os resultados da TEPP para obter a) evidências de validade baseadas na relação com outras variáveis, do tipo critério (correlação com idade, e comparação de grupos por ano de escolaridade e sexo); b) evidências de validade baseadas em construtos conceitualmente relacionados (convergente) por meio de correlações da TEPP com o Ditado Balanceado (MOOJEN, 2009) e com o Instrumento de Avaliação Neuropsicológica Breve Infantil - NEUPSILIN - Inf (SALLES et al., 2016); e c) dados normativos da TEPP em percentis para alunos de $4^{\circ}$ e $6^{\circ}$ anos do Ensino Fundamental.

Portanto, além de contribuir com as análises dos parâmetros psicométricos da TEPP, este estudo auxilia na ampliação dos dados normativos do instrumento. Desta forma, os profissionais que utilizam a TEPP, como psicólogos, psicopedagogos e professores, podem analisar e acompanhar o desempenho de crianças na escrita de palavras e propor as melhores estratégias de intervenção. A seguir, serão apresentados os pressupostos teóricos de base da TEPP e, na sequência, o método desta pesquisa.

\section{Tarefa de Escrita de Palavras e Pseudopalavras (TEPP)}

A TEPP é um instrumento que avalia a habilidade de escrita de palavras e pseudopalavras ditadas oralmente pelo examinador. É de fácil aplicação, composto por 72 estímulos divididos em frequentes (24 palavras) e não frequentes (24 palavras) e 24 pseudopalavras. Além disso, os grupos de estímulos estão organizados em regular, irregular, curtos e longos. Ela pode ser usada por psicólogos, fonoaudiólogos, médicos, terapeutas ocupacionais, psicopedagogos e professores, incluindo, assim, profissionais da área clínica, acadêmica e educacional.

A identificação da integridade das rotas de escrita (fonológica, lexical ou ambas) é a principal finalidade do instrumento, o que permite, deste modo, uma intervenção pontual, tanto a nivel preventivo como terapêutico ou educacional. Como bem destacam as autoras, esse teste, associado a outros instrumentos e técnicas neuropsicológicas de avaliação da linguagem (escrita e oral), pode auxiliar no diagnóstico de dificuldades de escrita e de disgrafias adquiridas e do desenvolvimento (RODRIGUES; MINÁ; SALLES, 2017).

$O$ instrumento tem como base teórica a neuropsicologia cognitiva, por meio do modelo cognitivo de dupla rota (COLTHEART, 2006). Conforme já discutido anteriormente, de acordo com este recurso, a escrita pode se dar por meio da rota fonológica (mediação fonológica) e/ou da rota lexical (acesso direto ao léxico).

$\mathrm{Na}$ rota fonológica os sons das palavras ditadas são convertidos em grafemas (conversão fonema-grafema). As palavras não familiares (ou não frequentes) e as pseudopalavras são escritas por meio da rota fonológica. A utilização da rota lexical se dá para a escrita de palavras familiares (ou frequentes) e irregulares (apresentam representações fonológicas ambíguas), ou seja, quando os estímulos ditados estão armazena- 
dos na memória lexical e, portanto, podem ser prontamente acessados e escritos (ELLIS, 1995).

A análise do modelo de dupla rota possibilita verificar a precisão da escrita (acertos), os tipos de erros cometidos em cada estímulo, assim como a influência de efeitos psicolinguísticos. A avaliação da precisão da escrita é feita por meio de uma análise quantitativa em que o desempenho da amostra na TEPP é mensurado em função de diferentes critérios, como idade ou grupo etário, escolaridade ou anos de estudo, sexo, nivel socioeconômico, entre outras possiveis variáveis que garantem a validade de critério do instrumento e possibilitam a construção de normas (grupo normativo de referência).

A análise qualitativa é dada pela frequência dos tipos de erros que os participantes cometem na escrita (por exemplo, escrita espelhada, desconhecimento de regra, inversão de letra), o que auxilia na compreensão das dificuldades evidenciadas. Uma complementação dessa análise é dada pela observação de efeitos psicolinguísticos. Eles referem-se, por exemplo, a verificação de: regularidade da correspondência fonema-grafema (as palavras regulares são escritas de forma mais rápida e acurada do que as irregulares), lexicalidade (palavras reais são acessadas mais rápida e precisamente do que pseudopalavras), extensão (palavras mais curtas são escritas com maior precisão do que as mais longas), frequência de ocorrência na língua (palavras frequentes e familiares são escritas mais rapidamente do que as de baixa frequência, não familiares e pseudopalavras), concretude (palavras concretas são acessadas com mais facilidade por apresentarem uma estrutura representacional clara na memória, em comparação a palavras abstratas), entre outros (SALLES; PARENTE, 2007).

Assim, o conjunto dos dados quantitativos e qualitativos proporcionados pela TEPP é capaz de elucidar o perfil de escrita dos participantes, contribuindo para suprir a lacuna referente à falta de instrumentos nacionais de avaliação da escrita, neste caso no nível da palavra, o que contribui para qualificar o processo de diagnóstico e interventivo. Neste artigo, o foco recai sobre a análise quantitativa do desempenho na TEPP de alunos de $4^{\circ}$ e $6^{\circ}$ anos do Ensino Fundamental, assim como a análise qualitativa dos efeitos psicolinguísticos dos estímulos.

A escolha por esta faixa de escolaridade justifica-se pelo fato de a partir do $4^{\circ}$ ano escolar as crianças já estarem aptas a escrever palavras ambiguas e irregulares de forma correta (CARDOSO-MARTINS, GONÇALVES, 2017; GUIMARÃES et al., 2019). Portanto, a TEPP poderia auxiliar na identificação de crianças nessas séries/anos escolares que ainda apresentam dificuldades para escrever estes tipos de estímulos.

\section{Método}

\subsection{Participantes}

A amostra foi composta por 181 alunos do Ensino Fundamental de quatro escolas da rede estadual do município de Porto Alegre, Rio Grande do Sul. Do total da amostra, havia 80 (44,2\%) meninos e 101 (55,8\%) meninas, com idades entre 9 e 12 anos. A amostra foi dividida em dois grupos, de acordo com seu ano escolar ( $4^{\circ}$ e $6^{\circ}$ anos). No grupo de estudantes de $6^{\circ}$ ano havia mais meninas e individuos com maior idade, em relação ao grupo de $4^{\circ}$ ano, conforme pode ser visualizado na Tabela 1.

Tabela 1 - Características demográficas dos participantes por grupos divididos por ano escolar

\begin{tabular}{lcccc}
\hline & $\begin{array}{c}\mathbf{4}^{\circ} \text { ano } \\
(\boldsymbol{n}=\mathbf{8 8})\end{array}$ & $\begin{array}{c}\mathbf{6}^{\circ} \text { ano } \\
(\boldsymbol{n}=\mathbf{9 3})\end{array}$ & $\mathbf{t} / \boldsymbol{\chi}^{\mathbf{2}}$ & $\mathbf{p}$ \\
\hline Idade & $9,89(0,76)$ & $11,4(0,49)$ & $-16,182$ & $<0,001$ \\
M (DP) & & & & \\
$\begin{array}{l}\text { Sexo } \\
\text { (F/Ma) }\end{array}$ & $42 / 46$ & $59 / 34$ & 4,527 & 0,033 \\
\hline
\end{tabular}

Nota: $\mathrm{M}$ = média, $\mathrm{DP}$ = desvio-padrão, $\mathrm{n}$ = número de participantes, $\mathrm{F}=$ feminino, $\mathrm{Ma}=$ masculino.

Foram incluidos apenas alunos que frequentavam a escola regular e não apresentavam indicadores de déficit intelectual, a partir dos resultados do Teste Matrizes Progressivas Coloridas de Raven (ANGELINI et al., 1999). Ainda, não foram incluídos participantes com histórico de alterações sensoriais (visual e/ou auditiva 
não corrigida), doenças crônicas, transtornos psiquiátricos, deficiência intelectual e doenças neurológicas.

\subsection{Procedimentos e Instrumentos}

Este estudo foi aprovado pelo Comitê de Ética e pelo Comitê de Pesquisa da Faculdade de Educação, da Universidade Federal do Rio Grande do Sul, sob o número 36205. Inicialmente, foi realizado o contato com as escolas, para posterior assinatura dos termos de consentimento livre e esclarecido (TCLE) pelos pais/responsáveis. Pais ou responsáveis pelo aluno responderam o Questionário socioeconômico (ABEP, 2016) e de saúde. Neste instrumento havia perguntas sobre os aspectos socioculturais, de saúde e de escolarização e permitiu excluir da amostra alunos com doenças neurológicas e/ou psiquiátricas (a partir do relato dos responsáveis).

Foi aplicado o Teste Matrizes Progressivas Coloridas de Raven coletivamente em pequenos grupos (ANGELINI et al., 1999), com o objetivo de avaliar o nivel de inteligência não verbal (QI) de cada estudante. Foi considerado o percentil 25 como ponte de corte para a exclusão dos estudantes com déficits intelectuais. Deste modo, foram incluídos na amostra os participantes que obtiveram o desempenho igual ou superior ao percentil 25, considerado intelectualmente médio, comparando os resultados de cada participante ao de individuos de escolas públicas brasileiras.

Com o objetivo de avaliar as habilidades ortográficas, foi administrado, coletivamente, o Ditado Balanceado (MOOJEN, 2009). As palavras são ditadas para os participantes escreverem no papel, e pronunciadas da forma como são faladas na região de aplicação do instrumento. Ele contém 50 palavras (dissilabas, trissilabas e polissilabas) divididas em regulares, irregulares e regidas por regras contextuais da escrita. A escolha dos vocábulos para compor o ditado seguiu critérios do tipo: ser de uso corrente, propiciar ambiente para a ocorrência da maioria das dificuldades ortográficas e refletir a frequência de uso da letra no vocabulá- rio da Lingua Portuguesa. Destaca-se que não são apresentados os critérios fonológicos, morfológicos e lexicais que compõem o Ditado Balanceado. A análise do instrumento considera a quantidade e o tipo de erro ortográfico evidenciado por nivel de escolaridade. As categorias de Moojen (2009) que compreendem os tipos de erro são: conversor fonema-grafema (substituições, omissões, adições, transposições ou inversões de letras), regras contextuais (existência de determinadas regras que definem o valor do grafema no contexto) e irregularidades da lingua (arbitrariedades na ortografia). Para fins deste estudo, foi analisado o escore total de erros dos alunos. Para analisar o escore $Z$ de desempenho de cada participante, como o instrumento foi normatizado para alunos de $3^{\mathrm{a}}$ a $8^{\mathrm{a}}$ série, foi realizada a correspondência entre as médias padronizadas de acordo com a equivalência entre série e ano $\left(3^{\mathrm{a}}\right.$ série $/ 4^{\circ}$ ano; $5^{\text {a }}$ série $/ 6^{\circ}$ ano).$^{4}$

Posteriormente, os participantes realizaram a TEPP (RODRIGUES; MINÁ; SALLES, 2017) aplicada em pequenos grupos. As palavras e as pseudopalavras foram pronunciadas de acordo com a forma habitual da região, evitando salientar ou pausar em demasia partes do estímulo-alvo. A partir de uma análise quantitativa dos escores brutos foram contabilizados os números de acertos em cada um dos 72 estímulos. Para considerar como acerto, as palavras deveriam ser escritas exatamente como o modelo do Protocolo de Aplicação. Em relação às pseudopalavras, foram aceitas como corretas diferentes maneiras que não violassem as regras do português brasileiro (por exemplo, cheno, xeno, chenu ou xenu; feci, fessi ou fesci). A aplicação desta tarefa ocorreu em um encontro com duração aproximada de 20 minutos.

Para fins de análise de dados da TEPP, foi utilizado a porcentagem de acertos em cada grupo de estímulos (palavras reais, regulares, irregulares, pseudopalavras, curtas e longas) e no total da tarefa. Ainda, foram avaliados os efeitos psicolinguísticos entre os grupos. Efeito de frequência foi verificado pela subtração da

\footnotetext{
4 A Lei $n^{\circ}$ 11.274, de 06 de fevereiro de 2006 (BRASIL, 2006), institui mudanças no Ensino Fundamental no Brasil. Com isso, ele passou de oito para nove anos. Houve também alterações na idade de ingresso e na distribuição de séries para anos escolares.
} 
porcentagem de acertos das palavras frequentes e não frequentes; efeito de regularidade foi identificado pela subtração da porcentagem de acertos de palavras regulares e irregulares; efeito de extensão pela subtração da porcentagem de acertos das palavras curtas e longas (para palavras e pseudopalavras); e efeito de lexicalidade foi encontrado pela subtração da porcentagem de acertos das palavras reais e pseudopalavras.

A última etapa da coleta de dados abrangeu a aplicação individual do Instrumento de Avaliação Neuropsicológica Breve Infantil NEUPSILIN-Inf (SALLES et al., 2016). O NEUPSILIN-Inf é uma bateria breve que avalia componentes de oito funções neuropsicológicas principais: orientação (tempo e espaço), percepção (visual de figuras e de faces), atenção (visual e auditiva), memória (episódico-semântica visual e verbal, operacional/de trabalho e semântica), linguagem (consciência fonológica, compreensão oral e escrita, processamento de inferências, leitura, escrita espontânea, copiada e sob ditado), habilidades visuoconstrutivas (cópia de figuras), habilidades aritméticas (contagem e cálculos) e funções executivas (fluência verbal), distribuidas em 26 subtestes. O NEUPSILIN-Inf possui normatização para as escolas públicas de Porto Alegre, sendo calculado o escore $Z$ de cada aluno, a fim de verificar seu desempenho em acertos neste instrumento. A aplicação individual teve duração de aproximadamente 50 minutos (por aluno).

\subsection{Análise de dados}

Para verificar as evidências de validade baseadas na relação com outras variáveis, do tipo critério (validade concorrente) da TEPP foi realizada análise de correlação de Spearman $(p<0,05)$ com os escores em porcentagem do instrumento (total, palavras reais, regulares, irregulares, curtas, longas, frequentes e não frequentes; pseudopalavras, curtas e longas), além dos efeitos psicolinguísticos (regularidade, frequência, extensão e lexicalidade), e a idade dos participantes. Para buscar essa evidência de validade também foi realizada a comparação do desempenho de grupos de alunos divididos por sexo e por ano escolar na TEPP (escores em porcentagem e efeitos psicolinguísticos), utilizando teste não-paramétrico de Mann-Whitney $(\mathrm{p}<0,05)$, devido a não normalidade dos dados.

Para analisar as evidências de validade baseadas em construtos conceitualmente relacionados (validade convergente), realizou-se análise de correlação de Spearman $(p<0,05)$ entre os escores em porcentagem da TEPP, escore $Z$ dos erros na tarefa de Ditado Balanceado e o desempenho em escores Z do desempenho no NEUPSILIN-Inf. Para interpretar os indices de correlação foram considerados valores entre o a 0,39 como correlação fraca, 0,40 a 0,69 correlação moderada, 0,70 a 0,89 correlação forte e valores maiores que 0,9 como correlação muito forte (Callegari-Jacques, 2003). Por fim, são apresentados dados normativos em percentis de desempenho dos alunos divididos em grupos por ano escolar ( $4^{\circ}$ e $6^{\circ}$ anos) na TEPP.

\section{Resultados}

4.1 Evidências de validade baseadas em critério: correlações da TEPP com idade e comparações de grupos

Encontraram-se correlações significativas, positivas e fracas, entre a idade dos participantes e a porcentagem de acertos na escrita das palavras reais $(\rho=0,284 ; p<0,001)$, regulares $(\rho=0,243 ; p$ $=0,001)$, irregulares $(\rho=0,272 ; p<0,001)$, curtas ( $\rho=0,266 ; p<0,001)$, longas $(\rho=0,259 ; p<0,001)$, frequentes $(\rho=0,274 ; p<0,001)$, não frequentes $(\rho$ $=0,255 ; p=0,001)$ e no total da TEPP $(\rho=0,237 ; p$ = 0,001). Portanto, quanto maior a idade, melhor o desempenho na escrita desses estímulos.

Encontrou-se correlação significativa, fraca e negativa entre a idade dos participantes e o efeito de regularidade $(\rho=-0,200 ; p=0,007)$. Assim, quanto maior a idade, menores diferenças são encontradas na porcentagem de acertos dos estímulos regulares comparados aos irregulares.

Não foram identificadas correlações estatisticamente significativas entre a idade dos participantes e o desempenho na escrita de pseudopalavras, curtas e longas, e nos efeitos de extensão das palavras reais, de frequência, de lexicalidade e de extensão das pseudopalavras. Em sintese, 
quanto mais idade dos participantes mais altos são os escores na TEPP (exceto na pseudopalavras) e mais baixo é o efeito de regularidade.

Para buscar a evidência de validade baseada em critério também foi realizada a comparação do desempenho de grupos de alunos divididos por sexo e por ano escolar na TEPP. Na comparação dos grupos por ano escolar ( $4^{\circ}$ e $6^{\circ}$ anos) foram encontradas diferenças estatisticamente significativas em todas as medidas da TEPP, exceto nos efeitos de extensão e frequência das palavras reais e na porcentagem de acertos das pseudopalavras curtas. Verificou-se que o grupo de maior escolaridade apresentou os mais altos escores na TEPP, conforme pode ser visualizado na Tabela 2.

Tabela 2 - Comparações entre os grupos divididos por ano escolar no desempenho (porcentagem de acertos) nas variáveis da TEPP, apresentadas em média, desvio-padrão, mínimo e máximo

\begin{tabular}{|c|c|c|c|c|c|c|c|}
\hline & $\begin{array}{l}4^{\circ} \\
(n=\end{array}$ & $\begin{array}{c}\text { ano } \\
88)\end{array}$ & $\begin{array}{l}6^{\circ} \\
(n=\end{array}$ & $\begin{array}{c}\text { ano } \\
93)\end{array}$ & & & \\
\hline TEPP & $M(D P)$ & Mín-Máx & $M(D P)$ & Min-Máx & $\boldsymbol{U}$ & $\begin{array}{c}\text { Estatística } \\
\text { de Teste } \\
\text { Padronizado }\end{array}$ & $p$ \\
\hline Palavras & $71,97(12,95)$ & $25-93,75$ & $83,26(8,02)$ & $58,33-100$ & 6240,5 & 6,111 & $<0,001^{* *}$ \\
\hline Regulares & $85,70(10,79)$ & $29,17-100$ & $92,42(5,72)$ & $75,00-100$ & 5860,5 & 5,096 & $<0,001^{* *}$ \\
\hline Irregulares & $58,23(17,17)$ & $20,83-91,67$ & $74,10(12,06)$ & $33.33-100$ & 6227 & 6,082 & $<0,001^{\star *}$ \\
\hline Curtas & $76,32(12,66)$ & $41,67-95,83$ & $87,14(7,56)$ & $62,50-100$ & 6192 & 6,016 & $<0,001^{*}$ \\
\hline Longas & $67.51(15.50)$ & $8,33-91,67$ & $79,39(10,46)$ & $54,17-100$ & 5981,5 & 5.393 & $<0,001^{* *}$ \\
\hline Frequentes & $81,39(12,96)$ & $41,67-100$ & $91,84(8,15)$ & $62,50-100$ & 6121 & 5,814 & $<0,001^{* *}$ \\
\hline $\begin{array}{l}\text { Não } \\
\text { frequentes }\end{array}$ & $61,93(15,15)$ & $8,33-91,67$ & $74,68(11,06)$ & $50,00-100$ & 6081,5 & 5,675 & $<0,001^{* *}$ \\
\hline $\begin{array}{l}\text { Efeito de re- } \\
\text { gularidade }\end{array}$ & $27,46(12,30)$ & $4,17-58,33$ & $18,32(9,96)$ & $-8,33-50,00$ & 2302,5 & $-5,095$ & $<0,001^{* *}$ \\
\hline $\begin{array}{l}\text { Efeito de } \\
\text { extensão }\end{array}$ & $8,80(11,55)$ & $-20,83-45,83$ & $7,75(8,72)$ & $-12,50-29,17$ & 3978,5 & $-0,324$ & 0,746 \\
\hline $\begin{array}{l}\text { Efeito de } \\
\text { frequência }\end{array}$ & $19,46(11,15)$ & $-4,27-50,00$ & $17,15(10,95)$ & $-4,17-45,83$ & 3554 & $-1,531$ & 0,126 \\
\hline $\begin{array}{l}\text { Efeito de } \\
\text { lexicalidade }\end{array}$ & $3,17(12,96)$ & $-33,33-45,83$ & $9,34(14.34)$ & $-22,92-45,83$ & 5054,5 & 2,734 & $0,006^{* *}$ \\
\hline $\begin{array}{l}\text { Pseudopa- } \\
\text { lavras }\end{array}$ & $68,79(15,22)$ & $25,00-91,67$ & $73.92(13.91)$ & $41,67-100$ & 4929,5 & 2,389 & $0,017^{*}$ \\
\hline Curtas & $73,48(14,81)$ & $25,00-91,67$ & $74,55(14,76)$ & $41,67-100$ & 4264.5 & 0,499 & 0,617 \\
\hline Longas & $64,10(20,38)$ & $0,00-91,67$ & $73,29(17,31)$ & $25-100$ & 5175.5 & 3,113 & $0,002^{* *}$ \\
\hline $\begin{array}{l}\text { Efeito de } \\
\text { extensão }\end{array}$ & $9,37(18,51)$ & $-41,67-50,00$ & $1,25(16,15)$ & $-41,67-100$ & 3217,5 & $-2,503$ & $0,012^{*}$ \\
\hline Total & $70,91(12,32)$ & $25,00-90,28$ & $80,15(7,85)$ & $62,50-95,83$ & 5999 & 5,148 & $<0,001^{* *}$ \\
\hline
\end{tabular}

Nota. $M$ = média, $D P$ = desvio-padrão; Min = mínimo; Máx = máximo; $\mathrm{n}$ = número de participantes.

${ }^{*}=p<0,05 ;{ }^{* *}=p<0,01$. 
Ao dividir os grupos por ano escolar em subgrupos por sexo (masculino e feminino) foram encontradas diferenças estatisticamente significativas em algumas medidas da TEPP, conforme observado na Tabela 3. No grupo de estudantes do $4^{\circ}$ ano escolar, identificou-se que as meninas apresentaram melhor desempenho na escrita de palavras curtas, em comparação aos meninos
(Tabela 3). No grupo de $6^{\circ}$ ano escolar as meninas demonstraram melhor desempenho, em relação aos meninos, na escrita de palavras reais, irregulares, longas, frequentes e um menor efeito de lexicalidade. Por outro lado, os meninos do $6^{\circ}$ ano apresentaram maior efeito de regularidade (maiores escores na escrita das palavras regulares em relação às irregulares) (Tabela 3).

Tabela 3 - Comparações entre os grupos por ano escolar divididos em subgrupos por sexo no desempenho (porcentagem de acertos) nas variáveis da TEPP, apresentadas em média e desvio-padrão

\begin{tabular}{|c|c|c|c|c|c|c|c|c|c|c|}
\hline & & $4^{\circ}$ & $\begin{array}{l}\text { ano } \\
(D P)\end{array}$ & & & & & $\begin{array}{l}\text { ano } \\
(D P)\end{array}$ & & \\
\hline TEPP & $\begin{array}{c}\text { Masculino } \\
(n=46)\end{array}$ & $\begin{array}{c}\text { Feminino } \\
(n=42)\end{array}$ & $\boldsymbol{U}$ & $\begin{array}{c}\text { Estatística } \\
\text { de Teste } \\
\text { Padronizado }\end{array}$ & $p$ & $\begin{array}{c}\text { Masculino } \\
(n=34)\end{array}$ & $\begin{array}{c}\text { Feminino } \\
(n=59)\end{array}$ & $\boldsymbol{U}$ & $\begin{array}{c}\text { Estatistica } \\
\text { de Teste } \\
\text { Padronizado }\end{array}$ & $p$ \\
\hline Palavras & $70,29(11,39)$ & $73,80(14,38)$ & 1182 & 1,808 & 0,071 & $80,75(8,61)$ & $84,71(7,35)$ & 1267.5 & 2,118 & $0,034^{*}$ \\
\hline Regulares & $84,78(8,75)$ & $86,70(12,69)$ & 1181 & 1,821 & 0,069 & $91,17(5,78)$ & $93,15(5,62)$ & 1217.5 & 1,755 & 0,079 \\
\hline Irregulares & $55.79(16,16)$ & $60,91(18,03)$ & 1144.5 & 1,495 & 0,135 & $70,34(12,67)$ & $76,27(11,24)$ & 1265 & 2,105 & $0,035^{*}$ \\
\hline Curtas & $73,55(11,95)$ & $79,36(12,85)$ & 1235.5 & 2,264 & $0,024^{*}$ & $85,29(8,15)$ & $88,20(7,05)$ & 1234.5 & 1,884 & 0,060 \\
\hline Longas & $66,84(12,87)$ & $68,25(18,08)$ & 1101,5 & 1,138 & 0,255 & $76,22(10,63)$ & $81,21(10,00)$ & 1265.5 & 2,113 & $0,035^{*}$ \\
\hline Frequentes & $79,34(12,45)$ & $83,63(13,28)$ & 1175 & 1,755 & 0,079 & $89.09(9.99)$ & $93,43(6,43)$ & 1254.5 & 2,050 & $0,040^{*}$ \\
\hline $\begin{array}{l}\text { Não } \\
\text { frequentes }\end{array}$ & $60,05(13,31)$ & $63.98(16,86)$ & 1172,5 & 1,730 & 0,084 & $72,42(10,56)$ & $75,99(11,22)$ & 1,221 & 1,753 & 0,080 \\
\hline $\begin{array}{l}\text { Efeito de } \\
\text { regulari- } \\
\text { dade }\end{array}$ & $28,98(12,48)$ & $25,79(12,04)$ & 847 & $-0,996$ & 0.319 & $20,83(9,56)$ & $16,87(9,98)$ & 747 & $-2,053$ & $0,040^{*}$ \\
\hline $\begin{array}{l}\text { Efeito de } \\
\text { extensão }\end{array}$ & $6,70(10,29)$ & $11,11(12,50)$ & 1118 & 1,277 & 0,202 & $9,06(7,91)$ & $6.99(9,13)$ & 838 & $-1,332$ & 0,183 \\
\hline $\begin{array}{l}\text { Efeito de } \\
\text { frequência }\end{array}$ & $19,29(12,43)$ & $19,64(9,70)$ & 969.5 & 0,029 & 0,977 & $16,66(11,23)$ & $17,44(10,87)$ & 1041 & 0,304 & 0,761 \\
\hline $\begin{array}{l}\text { Efeito de } \\
\text { lexicali- } \\
\text { dade }\end{array}$ & $2,17(15,56)$ & $4,26(9,40)$ & 1088 & 1,020 & 0,308 & $3,67(12,78)$ & $12,60(14,27)$ & 1333 & 2,635 & $0,008^{* \star}$ \\
\hline $\begin{array}{l}\text { Pseudo- } \\
\text { palavras }\end{array}$ & $68,11(15,09)$ & $69.54(15.52)$ & 1044 & 0,655 & 0.513 & $77,08(11,70)$ & $71,18(17,11)$ & 828.5 & $-1,400$ & 0,161 \\
\hline Curtas & $73,00(15,73)$ & $74,00(13,92)$ & 993 & 0,230 & 0,818 & $77,20(11,29)$ & $73,02(16,32)$ & 895 & $-0,881$ & 0,378 \\
\hline Longas & $63,22(19,29)$ & $65,07(21,71)$ & 1050 & 0,715 & 0,475 & $76.96(17,29)$ & $71,18(17,11)$ & 800 & $-1,644$ & 0,100 \\
\hline $\begin{array}{l}\text { Efeito de } \\
\text { extensão }\end{array}$ & $9,78(18,11)$ & $8,93(19,16)$ & 924.5 & -0.349 & 0,727 & $0,24(17,46)$ & $1,83(15,48)$ & 1051,5 & 0,391 & 0,696 \\
\hline Total & $69,56(10,42)$ & $72,38(14,09)$ & 1161,5 & 1,636 & 0,102 & $79.53(7,67)$ & $80,50(8,00)$ & 1082,5 & 0,635 & 0.525 \\
\hline
\end{tabular}

Nota. $\mathrm{M}=$ média, $\mathrm{DP}=$ desvio-padrão; $\mathrm{n}$ = número de participantes.

${ }^{*}=p<0,05 ;{ }^{* *}=p<0,01$. 


\subsection{Evidências de validade baseadas em construtos conceitualmente relacionados (validade convergente) da TEPP}

$\mathrm{Na}$ análise de correlação entre os escores de acertos em porcentagem da TEPP e do escore $Z$ do total de erros dos participantes na tarefa de Ditado Balanceado encontraram-se correlações significativas, negativas, fracas, variando de moderadas a fortes, na escrita de palavras reais $(\rho=-0,750 ; p<0,001)$, regulares $(\rho=-0,675 ; p<$ $0,001)$, irregulares $(\rho=-0,714 ; p<0,001)$, curtas $(\rho$ $=-0,663 ; p<0,001)$, longas $(\rho=-0,714 ; p<0,001)$, frequentes $(\rho=-0,665 ; p<0,001)$, não frequentes $(\rho=-0,649 ; p<0,001)$, pseudopalavras $(\rho=-0,382$; $p<0,001)$, pseudopalavras curtas $(\rho=-0,233 ; p$ $<0,001)$, pseudopalavras longas $(\rho=-0,393 ; p<$ $0,001)$, total da TEPP $(\rho=-0,714 ; p<0,001)$ e efeito de lexicalidade $(\rho=-0,253 ; p<0,001)$. Ainda, foram identificadas correlações significativas, positivas, fracas e moderadas entre os erros no Ditado Ba- lanceado e os efeitos de regularidade $(\rho=0,503$; $p<0,001)$, extensão das palavras reais $(\rho=0,163$; $p=0,028)$ e extensão das pseudopalavras ( $\rho=$ $0,234: p<0,001$ ). Não houve correlações significativas apenas entre os erros da tarefa de Ditado Balanceado e o efeito de frequência na TEPP.

Foram encontradas correlações significativas, positivas, variando de fracas a moderadas, entre a escrita das palavras reais, pseudopalavras e no total da porcentagem de acertos da TEPP e das tarefas do NEUPSILIN-Inf que avaliam a linguagem, habilidades visuoconstrutivas, aritmética e funções executivas (Tabela 4). Correlação significativa, negativa e fraca foi encontrada entre o domínio percepção e o escore total da TEPP. A atenção visual correlacionou-se de forma fraca e positiva apenas com a escrita de palavras reais, enquanto a memória mostrou correlação fraca e positiva somente com o escore total da TEPP, conforme pode ser visualizado na Tabela 4.

Tabela 4 - Correlações entre funções neuropsicológicas do NEUPSILIN-Inf e a TEPP

\begin{tabular}{lcccccc}
\hline NEUPSILIN-Inf/ TEPP & Palavras & $\boldsymbol{p}$ & Pseudopalavras & $\boldsymbol{p}$ & Total TEPP & $\boldsymbol{p}$ \\
\hline Orientação & $-0,083$ & 0,266 & 0,052 & 0,489 & $-0,040$ & 0,595 \\
Percepção & $-0,246$ & 0,001 & $-0,106$ & 0,156 & $-0,215$ & $0,004^{* *}$ \\
Atenção & 0,168 & $0,024^{*}$ & 0,016 & 0,829 & 0,116 & 0,120 \\
Memória & 0,145 & 0,052 & 0,122 & 0,102 & 0,152 & $0,041^{*}$ \\
Linguagem & 0,530 & $0,001^{* *}$ & 0,411 & $0,001^{* *}$ & 0,556 & $0,001^{* *}$ \\
Habilidades visuo- & 0,298 & $0,001^{* *}$ & 0,104 & 0,162 & 0,267 & $0,001^{* *}$ \\
construtivas & 0,309 & $0,001^{*}$ & 0,152 & $0,041^{*}$ & 0,297 & $0,001^{* *}$ \\
Habilidades aritméticas & 0,230 & $0,002^{* *}$ & 0,135 & 0,069 & 0,209 & $0,005^{* *}$ \\
Funções executivas & & & & &
\end{tabular}

${ }^{*}=p<0,05 ;{ }^{* *}=p<0,01$.

\subsection{Dados normativos da TEPP para alunos de $4^{\circ}$ e $6^{\circ}$ anos}

Dados normativos em percentis foram desenvolvidos a partir dos grupos divididos por ano escolar ( $4^{\circ}$ e $6^{\circ}$ anos). Embora tenham sido encontradas diferenças estatisticamente significativas em algumas medidas da TEPP entre os subgrupos por sexo, verificou-se que esta variável não estava interferindo nos resultados na maioria dos escores do instrumento. Além dos percentis, são apresentadas as médias e desvios-padrão dos escores dos participantes na análise quantitativa da TEPP (Tabelas 5 e 6). 
Tabela 5 - Normas dos escores de acertos na TEPP para o grupo do $4^{\circ}$ ano escolar $(n=88)$

\begin{tabular}{|c|c|c|c|c|c|c|c|c|c|c|c|}
\hline \multirow{2}{*}{ Percentil } & \multicolumn{11}{|c|}{ Escores de acertos } \\
\hline & Palavras & Regulares & Irregulares & Curtas & Longas & Frequentes & $\begin{array}{c}\text { Não } \\
\text { frequentes }\end{array}$ & Pseudopalavras & Curtas & Longas & Total TEPP \\
\hline 2,5 & 21,00 & 13,23 & 5,23 & 12,00 & 5,23 & 14,00 & 7,00 & 6,00 & 3,23 & 1,23 & 27,45 \\
\hline 7 & 26,00 & 17,00 & 8,00 & 13,23 & 11,23 & 14,23 & 10,00 & 9,46 & 6,00 & 3,23 & 37,23 \\
\hline 10 & 26,90 & 17.90 & 9,00 & 14,00 & 12,00 & 15,00 & 10,00 & 11,90 & 6,00 & 4,90 & 39,00 \\
\hline 16 & 28,00 & 19,00 & 9,00 & 15,00 & 13,00 & 16,00 & 11,00 & 13,24 & 7,00 & 5,00 & 44,00 \\
\hline 20 & 29,00 & 19,00 & 10,00 & 15,80 & 13,80 & 16,80 & 12,00 & 14,00 & 8,00 & 6,00 & 45,80 \\
\hline 30 & 31,00 & 20,00 & 11,00 & 16,00 & 15,00 & 18,00 & 13,00 & 15,00 & 8,00 & 7,00 & 47,00 \\
\hline 40 & 33,00 & 20,00 & 13,00 & 18,00 & 15,60 & 19,00 & 14,00 & 16,00 & 9,00 & 7,00 & 49,60 \\
\hline 50 & 35,00 & 21,00 & 14,00 & 18,50 & 17,00 & 20,00 & 15,00 & 17,00 & 9,00 & 8,00 & 52,00 \\
\hline 60 & 36,40 & 21,00 & 15,00 & 19,00 & 17,00 & 21,00 & 16,00 & 18,00 & 9,40 & 9,00 & 54,00 \\
\hline 70 & 39,00 & 22,00 & 17,00 & 20,30 & 19,00 & 21,30 & 17,00 & 19,00 & 10,00 & 10,00 & 56,00 \\
\hline 80 & 40,00 & 23,00 & 18,00 & 21,00 & 20,00 & 23,00 & 18,20 & 20,00 & 10,00 & 10,00 & 59,00 \\
\hline 90 & 42,00 & 23,00 & 19,00 & 22,00 & 20,10 & 23,10 & 19,00 & 21,00 & 11,00 & 10,00 & 62,00 \\
\hline Média & 34,55 & 20,57 & 13.98 & 18,32 & 16,20 & 19,53 & 14,86 & 16,51 & 8,82 & 7,69 & 51,06 \\
\hline DP & 6,218 & 2,590 & 4,122 & 3,038 & 3,721 & 3,111 & 3,636 & 3,655 & 1,778 & 2,446 & 8,871 \\
\hline
\end{tabular}


Tabela 6 - Normas dos escores de acertos na TEPP para o grupo do $6^{\circ}$ ano escolar $(n=93)$

\begin{tabular}{|c|c|c|c|c|c|c|c|c|c|c|c|}
\hline \multirow{2}{*}{ Percentil } & \multicolumn{11}{|c|}{ Escores de acertos } \\
\hline & Palavras & Regulares & Irregulares & Curtas & Longas & Frequentes & $\begin{array}{c}\text { Não } \\
\text { frequentes }\end{array}$ & Pseudopalavras & Curtas & Longas & Total TEPP \\
\hline 2,5 & 29,40 & 19,00 & 9,70 & 15,35 & 13,35 & 15,70 & 12,35 & 10,00 & 5,00 & 4,00 & 45,35 \\
\hline 7 & 34,00 & 20,00 & 13,00 & 18,58 & 15,00 & 18,58 & 13.58 & 11,00 & 5,00 & 5,00 & 48,58 \\
\hline 10 & 35,00 & 20,00 & 14,00 & 19,00 & 15,40 & 19,40 & 14,00 & 13,00 & 6,00 & 5,40 & 49,00 \\
\hline 16 & 36,04 & 21,00 & 15,00 & 19,00 & 16,04 & 20,04 & 15,04 & 14,00 & 7,00 & 6,04 & 51,04 \\
\hline 20 & 37,00 & 21,00 & 16,00 & 20,00 & 17,00 & 21,00 & 16,00 & 15,00 & 7,80 & 7,00 & 53,00 \\
\hline 30 & 38,00 & 22,00 & 17,00 & 20,00 & 18,00 & 21,00 & 17,00 & 17,00 & 8,00 & 8,00 & 55,00 \\
\hline 40 & 39,00 & 22,00 & 17,00 & 21,00 & 19,00 & 22,00 & 17,00 & 17,00 & 9,00 & 9,00 & 56,60 \\
\hline 50 & 40,00 & 22,00 & 18,00 & 21,00 & 19,00 & 23,00 & 18,00 & 18,00 & 9,00 & 9,00 & 58,00 \\
\hline 60 & 41,00 & 23,00 & 19,00 & 22,00 & 20,00 & 23,00 & 18,40 & 19,00 & 10,00 & 10,00 & 59,40 \\
\hline 70 & 42,00 & 23,00 & 19,00 & 22,00 & 20,00 & 23,00 & 19,00 & 20,00 & 10,00 & 10,00 & 61,80 \\
\hline 80 & 43,00 & 23,00 & 20,00 & 22,00 & 21,00 & 24,00 & 21,00 & 21,00 & 10,00 & 11,00 & 63,00 \\
\hline 90 & 44,00 & 24,00 & 21,00 & 23,00 & 22,00 & 24,00 & 21,00 & 21,00 & 11,00 & 11,00 & 65,00 \\
\hline Média & 39,97 & 22,18 & 17,78 & 20,91 & 19,05 & 22,04 & 17,92 & 17,74 & 8,95 & 8,80 & 57,71 \\
\hline DP & 3,852 & 1,375 & 2,896 & 1,816 & 2,512 & 1,956 & 2,655 & 3.339 & 1,772 & 2,078 & 5,656 \\
\hline
\end{tabular}




\section{Discussão}

O presente estudo buscou ampliar as evidências de validade da TEPP ao analisar o desempenho de alunos do $4^{\circ}$ e $6^{\circ}$ ano escolar do Ensino Fundamental. No que diz respeito à idade, verificaram-se correlações positivas significativas, embora fracas, com a escrita das palavras reais (em todas as subcategorias: regulares e irregulares, curtas e longas, frequentes e não frequentes), além do total de acertos da TEPP. Considerando que a idade da amostra variou conforme o ano escolar tal correlação é esperada.

A escrita é um objeto cultural ensinado na escola, sendo esperado que quanto mais exposta à atividade de escrever a criança é, mais acertos ela apresenta em relação às diferentes categorias de estímulos de escrita (CAPELLINI et al., 2012). Portanto, a TEPP demonstra evidências de validade baseadas em critério, ao demonstrar que quanto maior a idade, melhor o desempenho dos estudantes.

O mesmo raciocínio pode se aplicar à correlação negativa significativa verificada entre a idade e o efeito de regularidade, isto é, quanto maior a idade, menor o efeito. Este resultado indica que as crianças que já adquiriram fluência na escrita de palavras conseguem superar as dificuldades de escrever palavras com correspondências fonema-grafema ambíguas (por exemplo, escrever corretamente a palavra "saxofone", que tem a letra " $x$ " representada pelo som "cs"). A regularidade da correspondência fonema-grafema facilita o acerto das crianças menos experientes com a atividade de escrever, do mesmo modo que, quanto maior a exposição à tarefa de escrever, mais o aluno tende a dominar a escrita de palavras irregulares, por meio do uso da rota lexical (CAPELLINI et al., 2012). Assim, o menor efeito de regularidade observado nos alunos de $6^{\circ}$ ano pode indicar um maior uso da rota lexical (utilizando a memória das palavras) na escrita destes estudantes (RODRIGUES; MINÁ; SALLES, 2017).

Na comparação dos grupos por escolaridade verificou-se que o grupo de $6^{\circ}$ ano apresentou os maiores escores na TEPP, o que também é esperado considerando que eles têm mais experiência com materiais escritos (CAPELLINI et al., 2012; MORAIS, 2009). A relação com o tempo de escolaridade foi verificada também entre participantes adultos, utilizando a TEPP. Em uma amostra de 104 adultos divididos em um grupo com até 10 anos de estudo, e outro com 11 anos ou mais de estudo formal, encontraram-se diferenças estatisticamente significativas entre os grupos em praticamente todas as variáveis da TEPP (RODRIGUES; MINÁ; SALLES, 2017). Portanto, as diferenças encontradas nos grupos de estudantes de $4^{\circ}$ e $6^{\circ}$ anos escolares na TEPP reforçam as evidências de validade baseadas na relação com o critério deste instrumento.

Verificou-se que os grupos de alunos desses dois níveis de escolaridade diferenciam-se significativamente em praticamente todas as medidas da TEPP, sendo que o grupo mais avançado apresentou um desempenho melhor. Contudo, na escrita das pseudopalavras curtas a porcentagem de acertos das crianças de ambos os anos escolares foi muito semelhante. $\mathrm{O} 4^{\circ}$ ano atingiu $73,48 \%$ de acertos, em média. Como o desempenho nesta modalidade de estímulos está relacionado ao uso da rota fonológica, é provável que crianças de $4^{\circ}$ ano não tenham realmente dificuldades com os itens curtos. A escrita de pseudopalavras longas demanda mais recursos de memória fonológica (componente fonológico da memória de trabalho) (GRAZZOTI et al., 2013). Desta forma, as pseudopalavras longas já apresentam resultados estatisticamente diferentes entre as crianças de cada ano escolar.

Algumas pesquisas se dedicam a estudar a categorização dos erros ortográficos em tarefas escritas. O estudo de Silva e Crenitte (2015) comparou o perfil ortográfico dos escolares do $4^{\circ}$ ao $6^{\circ}$ ano do Ensino Fundamental. Participaram 384 estudantes, sendo 206 de escolas privadas e 178 de escolas públicas. Os resultados mostraram que não são semelhantes os perfis dos erros ortográficos entre eles quanto ao $4^{\circ}$ e ao $6^{\circ}$ ano. As autoras consideraram que os erros ortográficos são superados de forma gradativa com o avanço na escolaridade, entretanto, a superação entre $04^{\circ}$ e $5^{\circ}$ ano do ensino público foi considerável. Mota et al. (2000) analisaram os erros cometi- 
dos na escrita em uma redação por adolescentes. Os resultados quantitativos mostraram a importância da aquisição do princípio alfabético e sua consolidação, pois muitos erros encontrados foram associados por uma simples aplicação de regras de correspondência entre fonema e grafema, desconsiderando o fato de que a escrita de algumas palavras depende de regras ortográficas mais complexas.

Os resultados também evidenciaram algumas diferenças estatisticamente significativas de desempenho conforme o sexo. Foram verificados escores superiores entre as meninas na escrita de palavras curtas no grupo de $4^{\circ}$ ano, e na escrita de palavras reais, irregulares, longas e frequentes, no grupo de $6^{\circ}$ ano. Neste grupo também apareceram diferenças quanto aos efeitos psicolinguísticos conforme o sexo: as meninas apresentaram um menor efeito de lexicalidade (não apresentam mais acertos nas palavras reais do que nas pseudopalavras), e os meninos apresentaram maior efeito de regularidade (escrevem com mais correção palavras regulares do que irregulares).

A literatura apresenta dados divergentes quanto à influência do sexo no desempenho escolar em medidas relacionadas às habilidades acadêmicas de leitura, escrita e matemática. Entretanto, os estudos que evidenciam a diferença de sexo, geralmente, apontam para a prevalência masculina entre as dificuldades de aprendizagem, ou escores mais baixos em diferentes medidas (CAPELLINI; TONELOTTO; CIASCA, 2004; FLETCHER et al., 2009; OSTI; MARTINELI, 2014).

Nas pesquisas que analisam a influência do sexo na aquisição das habilidades acadêmicas verifica-se, por exemplo, que meninos são maioria em grupo de alunos com desempenho insatisfatório entre estudantes de quinto ano do Ensino Fundamental - EF (OSTI; MARTINELI, 2014). Em alunos do $2^{\circ}$ e $4^{\circ}$ anos do EF, dificuldades de leitura, escrita e matemática apareceram associadas ao sexo masculino (CAPELLINI; TONELOTTO; CIASCA, 2004, 2004). Na revisão de Fletcher et al. (2009), verificou-se que os estudos que abordaram a razão de gênero especificamente em relação a dificuldades de escrita também não apresentaram resultados convergentes, alguns indicando a prevalência do sexo masculino, enquanto outros não a confirmaram. Na nossa amostra, a TEPP diferenciou meninos e meninas em relação a um único aspecto no $4^{\circ}$ ano, ampliando-se o espectro de estímulos no $6^{\circ}$ ano escolar em que os meninos apresentaram desempenho inferior. Contudo, ressalta-se o pequeno tamanho da amostra, e o fato de não terem sido controlados outros fatores como a frequência de hábitos de leitura e escrita dos estudantes, que podem influenciar nos resultados da escrita (RODRIGUES; MINÁ; SALLES, 2017).

Com esta amostra de crianças de $4^{\circ}$ e $6^{\circ}$ ano também foi possivel reunir evidências de validade de construto, dadas as correlações entre todas as medidas da TEPP (exceto no efeito de regularidade) e o Ditado Balanceado (DB), instrumento que também avalia a ortografia. As correlações significativas negativas (no DB pontuam-se os erros) foram mais fortes em relação às palavras reais da TEPP (regulares e irregulares, longas e curtas, frequentes e não frequentes), e fracas a moderadas em relação às pseudopalavras. Deve-se considerar que o Ditado Balanceado não inclui a escrita de pseudopalavras, o que justifica as fracas correlações. Portanto, estes resultados confirmam as evidências de validade baseadas em construtos conceitualmente relacionados da TEPP.

A análise de correlação entre a TEPP e o NEUPSILIN-Inf ofereceu, por sua vez, evidências de validade convergente e discriminante. Quando se escreve, recrutam-se simultaneamente os sistemas funcionais sensorial, motor, da linguagem oral, da memória e da atenção, que passam a trabalhar juntos nessa habilidade (BERNINGER; RICHARDS, 2002). As tarefas desse instrumento neuropsicológico infantil avaliam funções relacionadas à escrita, como a linguagem, as habilidades visuoconstrutivas, funções executivas e habilidades aritméticas, sendo encontradas correlações significativas com essas tarefas.

Assim como o NEUPSILIN-Inf, a TEPP mostrou relacionar-se com diversas funções neuropsicológicas do Instrumento de Avaliação Neuropsi- 
cológica Breve para Pacientes com Afasia de Expressão NEUPSILIN-Af em amostra de adultos (RODRIGUES; MINÁ; SALLES, 2017). Verificou-se, por exemplo, correlação entre a TEPP e os subtestes de linguagem oral e escrita.

Esta relação é esperada uma vez que essas tarefas envolvem ler, escrever, repetir e compreender palavras e frases, ou seja, habilidades relacionadas com a escrita de palavras e pseudopalavras (RODRIGUES; MINÁ; SALLES, 2017). Também entre adultos foi verificada correlação entre a TEPP e os subtestes de Aritmética. Com as duas amostras, a relação não surpreende, posto que para fazer cálculos no papel (conforme a tarefa usada neste estudo), o participante deve ouvir os números ditados e escrevê-los, para então resolver as contas (PIRES; SIMÃO, 2017).

Quanto às correlações significativas entre a TEPP, a memória, as funções executivas e as habilidades visuoconstrutivas, elas também eram esperadas, uma vez que a escrita sob ditado envolve necessariamente essas capacidades neuropsicológicas. A fim de detectar as funções neuropsicológicas alteradas, relacionando-as entre grupos com e sem dificuldades de aprendizagem, Pires e Simão (2017) avaliaram alunos do $1^{\circ}$ ao $3^{\circ}$ ano do Ensino Fundamental com dificuldades de aprendizagem na leitura, escrita e matemática e com defasagens em algumas habilidades cognitivas (inteligência não verbal) e em funções executivas.

Os resultados mostraram cinco funções cognitivas em que o grupo com dificuldade apresentou desempenho inferior: linguagem, memória, orientação, habilidades visuoconstrutivas e habilidades aritméticas. Os dados dessa pesquisa apontam a necessidade de uma completa avaliação neuropsicológica, que possibilite uma interpretação mais apurada das funções cognitivas e o adequado planejamento de intervenção para prevenir futuras dificuldades de aprendizagem e outros problemas associados ao baixo desempenho escolar (PIRES; SIMÃO, 2017).

Em se tratando dos processos ortográficos, a escrita partilha de recursos cognitivos (memória, linguagem, entre outros) que facilitam o estabele- cimento de estratégias com vistas à aprendizagem (EHRI, 1997). Assim, pode-se considerar que a TEPP demonstrou evidências de validade convergente com funções neuropsicológicas relacionadas às habilidades de escrita. Por outro lado, a tarefa não mostrou correlacionar-se com a função de orientação do NEUPSILIN-Inf, o que pode ter ocorrido tanto por haver poucos itens dela neste instrumento, o que influenciou na pouca variabilidade dos escores, assim como por esta capacidade neuropsicológica ser pouco recrutada na escrita sob ditado (validade divergente). Portanto, os resultados das análises com o NEUPSILIN-Inf reforçam as evidências de validade baseadas em construtos conceitualmente relacionados da TEPP.

Uma vez que a TEPP demonstrou adequadas evidências de validade para ser administrada em estudantes do $4^{\circ}$ e $6^{\circ}$ ano do Ensino Fundamental, considerou-se relevante apresentar dados normativos em percentis para clínicos e pesquisadores que aplicam o instrumento em contextos clínicos e educacionais. Embora tenham sido evidenciadas diferenças em algumas medidas da TEPP entre meninos e meninas, estas não foram em um amplo número de variáveis, além de não comprometer os escores em percentis.

Portanto, profissionais que utilizam a TEPP podem comparar os resultados do seu participante/estudante, a partir das tabelas disponiveis, conforme o ano escolar em que este se encontra no momento da avaliação. Considera-se como um indicador de escrita deficitária um percentil menor do que 25. Dessa forma, ao identificar dificuldades nesta habilidade, é fundamental que o profissional compreenda como ocorre a aquisição do conhecimento ortográfico e as relações entre o funcionamento cognitivo (CALIATTO; FERNANDES, 2014) para interferir e promover o aprendizado do estudante.

\section{Considerações finais}

Este estudo possibilitou a ampliação do conhecimento acerca das características psicométricas da TEPP, instrumento proposto, originalmente, para uso com adultos e idosos brasileiros. Professores podem se beneficiar da leitura deste artigo ao consultarem o desempenho de alunos 
de $4^{\circ}$ e $6^{\circ}$ anos do Ensino Fundamental em uma tarefa de ditado de palavras e pseudopalavras, verificarem as funções neuropsicológicas que estão relacionadas com a escrita e analisarem os dados que sugerem atraso na aprendizagem da escrita, utilizando as normas da TEPP.

Nesta investigação, a habilidade de escrita de palavras e pseudopalavras de 181 estudantes de $4^{\circ}$ ano e 93 estudantes de $6^{\circ}$ ano do Ensino Fundamental, de escolas públicas, foi avaliada com a TEPP, o que possibilitou mostrar evidências de validade do instrumento. Os escores do instrumento correlacionaram-se com idade, diferenciaram grupos por nivel de escolaridade e sexo.

Os achados apontaram maiores escores para os estudantes mais velhos e de maior escolaridade. Efeito de sexo também foi encontrado em algumas medidas da TEPP, com vantagem para as meninas, principalmente do $6^{\circ}$ ano escolar. Todos estes resultados reforçam as evidências de validade baseadas em critério do instrumento.

Evidências de validade convergente entre os escores na TEPP e os escores em Ditado balanceado eram esperadas, já que ambos os instrumentos medem o mesmo constructo (a escrita de palavras). Do mesmo modo, a validade convergente entre os escores na TEPP e os escores no NEUPSILIN-Inf também foi constatada, em especial no que diz respeito às funções neuropsicológicas relacionadas à linguagem escrita, reforçando as evidências de validade baseadas em construtos conceitualmente relacionados.

Por fim, são apresentados os dados normativos da TEPP, considerando os dois anos escolares dos participantes. Conforme já destacado, os dados normativos são cruciais para auxiliar o avaliador no processo de dimensionar o desempenho do aluno na TEPP, a partir de uma amostra normativa.

Convém lembrar, no entanto, que tais normas representam a amostra para a qual o instrumento foi aplicado, e não são absolutas, universais ou permanentes (ANASTASI; URBINA, 2000). Portanto, é prudente cautela diante das comparações de casos avaliados com amostras normativas, sendo importante a complementação da avaliação com outros instrumentos, incluindo a escrita de sentenças e a produção textual, que propiciem dados tanto quantitativos como qualitativos em relação ao desempenho na escrita.

Uma abordagem de avaliação múltipla da escrita, com base em instrumentos válidos, pautados em princípios cientíicos permite ao avaliador fazer inferências mais confiáveis não só em relação ao desempenho do aluno/paciente, mas também quanto às estratégias, de caráter preventivo e/ou interventivo, a serem utilizadas. A TEPP pode ser aplicada por professores que desejam avaliar como está o desempenho da escrita de seu aluno em relação à turma, assim como em relação ao ano escolar que está inserido.

Os resultados deste estudo, juntamente com os apresentados por Rodrigues, Miná e Salles. (2017) reforçam que a TEPP é um potencial instrumento para a avaliação do processamento de escrita pelas rotas lexical e fonológica. Algumas limitações deste estudo referem-se ao fato de a tarefa não ter sido administrada em alunos do $5^{\circ}$ ano escolar e esta amostra ser apenas de escolas públicas. Ainda, ela foi construida com base em palavras que são frequentes para adultos, o que pode ter dificultado o desempenho dos alunos, principalmente na escrita de palavras irregulares.

Para estudos futuros, destaca-se a importância da realização de mais pesquisas com a TEPP, ampliando as normas para outros anos escolares, provenientes de escolas públicas e também privadas. Isso irá possibilitar o aprimoramento do instrumento, assim como interpretações mais seguras e coerentes com a realidade vivenciada.

\section{Referências}

AMERICAN PSYCHIATRIC ASSOCIATION (APA).. DSM-5: Manual diagnóstico e estatístico de transtornos mentais. 5. ed. Tradução de M. I. Nascimento. Porto Alegre: Artmed, 2013

ANGELINI, Arrigo et al.. Manual matrizes progressivas coloridas de Raven: escala especial. São Paulo: Centro Editor de Testes e Pesquisas em Psicologia, 1999.

ANASTASI, Anne; URBINA, Susana. Testagem psicológica. 7. ed. Porto Alegre: Artmed, 2000.

ARFÉ, Barbara; DOCKRELL, Julie; DE BERNARDI, Bianca. The effect of language specific factors on early written composition: the role of spelling, oral language and text generation skills in a shallow orthography. Reading and Writing, [S. I.], v. 29, n. 3, p. 501-527, jan. 2016. https:// doi.org/10.1007/s11145-015-9617-5 
ASSOCIAÇÃO BRASILEIRA DE EMPRESAS DE PESQUISA (ABEP). Critério de Calssificação Econômica. 2016. Disponivel em: www.abep.org/criterio-brasil. Acesso em: 11 jun. 2021.

BERNINGER, Virginia W.; RICHARDS, Todd L. Brain literacy for educators and psychologists. Rio de Janeiro: Elsevier, 2002.

BRASIL. Lei n. 11.274, de 6 de feveiro de 2006. Brasília: Presidência da República, 2006. Disponivel em: http:// www.planalto.gov.br/ccivil_03/ato2004-2006/2006/ lei/l11274.htm. Acesso em: 8 jun. 2021.

CALIATTO, Susana Gakyia; FERNANDES, Débora Cecílio. Análise pelo modelo de Rasch do ditado ADAPE: considerações da ortografia. Psico, Porto Alegre, v. 45, n. 2, p. 270-280, ago. 2014. https://doi.org/10.15448/19808623.2014.2.16820

CAPELLINI, Simone Aparecida et al. Desempenho ortográfico de escolares do $2^{\circ}$ ao $5^{\circ}$ ano do ensino particular. Revista CEFAC, São Paulo, v. 14, n. 2, p. 254-267, fev. 2012. http://dx.doi.org/10.1590/S151618462012005000012

CAPELLINI, Simone Aparecida; CONRADO, Talita Laura. Desempenho de escolares com e sem dificuldades de aprendizagem de ensino particular em habilidade fonológica, nomeação rápida, leitura e escrita. Revista CEFAC, São Paulo, v. 11, supl 2, p. 183-193, mar. 2009.

CAPELLINI, Simone Aparecida; TONELOTTO, Josiane Maria de Freitas, CIASCA, Sylvia Maria. Medidas de desempenho escolar: avaliação formal e opinião de professores. Estudos de Psicologia, Campinas, v. 21, n. 2, p. 79-90, ago. 2004. https://doi.org/10.1590/S0103166X2004000200006

CARDOSO-MARTINS, Claudia; GONÇALVES, Daniela. "Funil" ou "Funiu"?: um estudo exploratório sobre o desenvolvimento do conhecimento de padrões ortográficos de natureza morfossintática em português brasileiro. Da Investigação às Práticas, [S. I.], v. 7. n. 3 , p. 41-60, ago. 2017.

COLTHEART, Max. Dual route and connectionist models of reading: An overview. London Review of Education, [S. I.], v. 4, n. 1, p. 5-17, mar. 2006. https://doi. org/10.1080/13603110600574322

CORREA, Jane. Representações e competências desenvolvidas pela criança no aprendizado da escrita. In: LUNA, Maria José de Matos; SPINILLO, Alina; RODRIGUES, Siane Gois (org.). Leitura e Produção de Texto. Recife: Editora Universitária da UFPE, 2010. p. 13-49.

CORSO, Luciana V.; DORNELES, Beatriz V. Avaliação da Matemática: competências numéricas e competências de base. In: SCICCHITANO, Rosa Maria Junqueira; CASTANHO, Marisa Irene Siqueira (org.). Avaliação psicopedagógica: recursos para a prática. Rio de Janeiro: Wark Editora, 2013.

DORNELES, Beatriz Vargas et al. Impacto do DSM-5 no diagnóstico de transtornos de aprendizagem em crianças e adolescentes com TDAH: um estudo de prevalência. Psicologia Reflexão \& Crítica, [S. I.], v. 27. p. 759-767, dez. 2014.
ELLIS, Andrew. Leitura, escrita, dislexia: uma análise cognitiva. Porto Alegre: Artes Médicas, 1995.

EHRI, L. C. Learning to read and learning to spell are one and the same, almost. In: PERFETTI, C.; RIEBEN, L.; FAYOL, M. Learning to Spell: Research, Theory and Practice Across Languages. Mahwah: Erlbaum, 1997. p. 237-269.

FLETCHER, Jack et al.. Transtornos de aprendizagem: da identificação à intervenção. Porto Alegre: Artmed, 2009.

GRANZOTTI, Raphaela Barroso Guedes et al. Memória de trabalho fonológica e consciência fonológica em crianças com dificuldade de aprendizagem. Distúrbios da Comunicação, [S. I.], v. 25, n. 2, p. 241-252, 2013.

GUIMARÃES, Sandra Regina Kirchner et al. Parâmetros Psicométricos da Prova de Consciência Morfológica Derivacional. Psico-USF, [S. I.], v. 24, n. 4, p. 725-736, out. 2019.

INSTITUTO NACIONAL DE ESTUDOS E PESQUISAS EDUCACIONAIS ANISIO TEIXEIRA (INEP). Relatório SAEB/ANA 2016: panorama do Brasil e dos estados. Brasília, DF: Ministério da Educação, 2018a. 239 p.

INSTITUTO NACIONAL DE ESTUDOS E PESQUISAS EDUCACIONAIS ANÍSIO TEIXEIRA (INEP). Press Kit: Saeb 2017. Brasilia: MEC/Inep, SAEB; 2018b. 37 p.

MALUF, Maria Regina; CARDOSO-MARTINS, Cláudia. Alfabetização no Século XXI: como se aprende a ler e a escrever. Porto Alegre: Penso, 2013.

MOOJEN, Sônia Maria Pallaoro. A escrita ortográfica na escola e na clínica: teoria, avaliação e tratamento. São Paulo: Casa do Psicólogo, 2009.

MORAIS, A. G. Ortografia: ensinar e aprender. 4. ed. São Paulo: Ática, 2009.

MOTA, Márcia da et al. Erros de escrita no contexto: uma análise na abordagem do processamento da informação. Psicologia Reflexão \& Crítica, [S. I.], v. 13. n. 1, p. 1-6, 2000. https://doi.org/10.1590/S010279722000000100002

OSTI, Andréia; MARTINELI, Selma de Cássia. Desempenho escolar: análise comparativa em função do sexo e percepção dos estudantes. Educação \& Pesquisa, IS. l.], v. 40, n. 1, p. 49-59, 2014.

PIRES, Ariane Bizzarri Costa; SIMÃO, Adriana Nobre de Paula. Avaliação de crianças com indicação de dificuldades de aprendizagem pelo instrumento NEUPSILIN-Inf. Revista Psicopedagógica, [S. I.], v. 34, n. 104, p. 148-157, 2017.

RIO GRANDE DO SUL. Secretaria da Educação do Estado do Rio Grande do Sul. Sistema de Avaliação do Rendimento Escolar do Rio Grande do Sul. Revista do sistema. Juiz de Fora: Universidade Federal de Juiz de Fora; Faculdade de Educação; CAEd, 2016. 68 p.

RODRIGUES, Jaqueline de Carvalho; MINÁ, Camila Schorr; SALLES, Jerusa Fumagalli. Tarefa de escrita de palavras e pseudopalavras - TEPP. São Paulo: Editora, 2017.

SALLES, Jerusa Fumagalli; PARENTE, Maria Alice de Mattos Pimenta. Processamento da linguagem em tarefas de memória. In: OLIVEIRA, Alcyr (org.). Memória, cognição e comportamento. Porto Alegre: Casa do Psicólogo, 2007. p. 231-256. 
SALLES, Jerusa Fumagalli; SBICIGO, Juliana Burges, MACHADO, Wagner de Lara, MIRANDA, Monica Carolina; FONSECA, Rochele Paz. Análise Fatorial Confirmatória do Instrumento de Avaliação Neuropsicológica Breve Infantil - NEUPSILIN-Inf. Psico-USF, IS. I], v. 19, n. 1, p. 119-30, abr. 2014. http://dx.doi.org/10.1590/S1413-82712014000100012

SALLES, Jerusa Fumagalli et al. Instrumento de avaliação neuropsicológica breve NEUPSILIN-Inf. São Paulo, SP: Vetor, 2016.

SILVA, Cláudia da; CAPELLINI, Simone Aparecida. Desempenho de escolares com e sem transtorno de aprendizagem em leitura, escrita, consciência fonológica, velocidade de processamento e memória de trabalho fonológica. Revista Psicopedagogia, [S. I.], v. 30, n. 91, p. 3-11, 2013

SILVA, Nathane Sanches Marques; CRENITTE, Patricia Abreu Pinheiro. Desempenho de crianças com risco para dificuldade de leitura submetidas a um programa de intervenção. CoDAS, [S. I.], v. 28, n. 5, p. 517-525, out. 2016. https://doi.org/10.1590/2317-1782/20162015274

\section{Jaqueline de Carvalho Rodrigues}

Mestre, Doutora e Pós-doutora em Psicologia pela Universidade Federal do Rio Grande do Sul (UFRGS). Especialista em Neuropsicologia (CFP). Professora Assistente da Escola de Saúde da Universidade do Vale do Rio dos Sinos (UNISINOS). Autora dos instrumentos "Tarefa de Escrita de Palavras e Pseudopalavra (TEPP)" e "Tarefa de Leitura de Palavras e Pseudopalavras (TLPP)".

\section{Lisiane França Garcia Franquilin Pereira}

Mestre em Educação (UFRGS); professora da UNIASSELVI, Departamento de Psicopedagogia e Neuropsicopedagogia. Coordena o projeto de estágios "Psicopedagogia e Neuropsicopedagogia: da avaliação à intervenção".

\section{Jerusa Fumagalli de Salles}

Doutora em Psicologia (UFRGS). Professora Associada do Instituto de Psicologia, PPG em Psicologia. Universidade Federal do Rio Grande do Sul - UFRGS. Coordenadora do Núcleo de Estudos em Neuropsicologia Cognitiva (Neurocog).

\section{Helena Vellinho Corso}

Doutora em Psicologia (UFRGS); professora da Faculdade de Educação da UFRGS, Departamento de Estudos Especializados. Coordena o projeto de pesquisa "Compreensão de leitura: avaliação e intervenção". Realizou estágio de doutoramento na Temple University - College Education, departamento Psychological Studies in Education (Philadelphia - PA - USA).

\section{Luciana Vellinho Corso}

Doutora em Educação; Professora Associada do Programa de Pós Graduação em Educação da Faculdade de Educação da Universidade Federal do Rio Grande do Sul (FACED/UFRGS),

Porto Alegre, RS, Brasil. Doutora em Educação pelo PPGEDU/UFRGS. Mestre em Educação pela Flinders University - Austrália. Coordenadora do projeto de pesquisa "Dificuldades de aprendizagem na matemática e na leitura: atraso no desenvolvimento ou déficit cognitivo?".

\section{Endereço para correspondência}

Jaqueline de Carvalho Rodrigues

Universidade do Vale do Rio dos Sinos

Av. Unisinos, 950

Cristo Rei, 93022-750

São Leopoldo, RS, Brasil 